\title{
Zastosowanie modelu tribowibroakustycznego do wyboru punktów pomiarowych i symptomów wibroakustycznych silnika spalinowego lokomotyw
}

\begin{abstract}
$W$ pracy przedstawiono sposób doboru punktów pomiaru sygnatów wibroakustycznych i wyboru informacyjnie efektywnych symptomów w oparciu o zbudowany model wibroakustyczny. Koncepcje zweryfikowano na przyktadzie silnika spalinowego 2112 SSF stosowanego do napędu lokomotyw spalinowych serii SP 45. Uzyskane wyniki wskazuja na to, że proponowana koncepcja może być dobrym uzupetnieniem analizy korelacyjnej, stosowanej dotychczas do wyboru punktów pomiarowych.
\end{abstract}

\section{Wprowadzenie}

W procesie diagnozowania stanu technicznego obiektów technicznych, zwłaszcza złożonych jakimi są niewątpliwe spalinowe silniki kolejowe, najbardziej istotne jest określenie stanu technicznego obiektu. W przypadku, kiedy silnik jest niesprawny, interesujące jest pytanie o przyczynę niesprawności, natomiast jeśli silnik jest sprawny, istotna jest prognoza horyzontu czasowego tego stanu. W diagnostyce obiektów technicznych stosuje się dwie grupy metod prognozowania. Pierwszą grupę stanowią metody prognozowania przy znanym modelu trendu symptomu diagnostycznego. Istota tych metod polega na tym, że znany jest model zmian symptomu (wyznaczony na podstawie danych eksperymentalnych), w oparciu o który szacuje się wartość symptomu dla zadanego horyzontu czasowego (przebiegu). Druga grupa metod dotyczy prognozowania, gdy model zmian symptomu nie jest znany. W takim przypadku prognozowanie polega na bieżącej budowie i ulepszaniu modelu trendu na podstawie kolejnych napływających danych o wartościach symptomu diagnostycznego. W artykule do wyboru punktów pomiarowych i symptomu wibroakustycznego w oparciu o wyniki prognozowania przyjęto metodę prognozowania przy znanym modelu zmian symptomu wibroakustycznego. Do prognozowania zasobu pracy do uszkodzenia zastosowano model tribowibroakustyczny zaproponowany przez Cempla [1], w którym rzeczywistą krzywą rozwoju unormowanego symptomu wibroakustycznego zastapiono dwuparametrowym rozkładem teoretycznym. W oparciu o wyniki zawarte w pracy [2] przyjęto rozkład Frecheta.

Celem pracy jest zastosowanie modelu tribowibroakustycznego do wyboru właściwego (właściwych) punktu pomiarowego i informacyjnie efektywnego symptomu wibroakustycznego na przykładzie kolejowego silnika spalinowego.

\section{Sformulowanie i sformalizowanie problemu}

Model rozwoju symptomu tribowibroakustycznego dla silnika można zapisać w postaci ogólnej:

$$
\frac{\mathrm{S}}{\mathrm{S}_{0}}=\Phi\left[(1-\mathrm{D})^{-1}\right]
$$

gdzie:

$\Phi$ - operator zależny od typu rozkładu krzywej ewolucji symptomu,

$\mathrm{S}$ - bieżąca wartość symptomu,

$\mathrm{S}_{0}$ - początkowa wartość symptomu.

W przypadku rozkładu Frecheta zależność (1) przyjmie postać:

$$
\frac{\mathrm{S}(\mathrm{D})}{\mathrm{S}_{\mathrm{o}}}=(-\ln \mathrm{D})^{-1 / \gamma}
$$

gdzie D jest operatorem będącym ilorazem wartości $\Theta$, która jest miarą czasu lub przebiegu w chwili t, do wartości $\Theta_{b}$, która jest czasem lub przebiegiem w chwili uszkodzenia obiektu. Ponieważ wielkość $\Theta_{\mathrm{b}}$ nie jest znana na początku obserwacji, a w każdym razie - w początkowej jej fazie, wartość tę można przyjąc na podstawie znajomości przebiegu do naprawy określonego przepisami (dla obserwowanych silników wynosi ona 300 tys. km) maksymalnego przebiegu, jaki dany obiekt może zrealizować (teoretycznie) lub na podstawie wyników badań niezawodności.

Badacz dysponuje zbiorem wyników pomiarów symptomów wibroakustycznych i odpowiadającym mu zbiorem zmiennych niezależnych $\mathrm{D}$, przeto zadanie identyfikacji modelu sprowadzić można do poszukiwania takiej wartości współczynnika kształtu $\gamma$ (współczynnik kształtu rozkładu), dla której błąd aproksymacji rzeczywistej krzywej $\mathrm{S}(\mathrm{D}) / \mathrm{S}_{\mathrm{o}} \mathrm{z}$ założonym rozkładem teoretycznym będzie najmniejszy.

Dla pierwszych dyskretnych wartości czasu obserwacji silnika (lub jego przebiegu) określa się wartości współczynnika kształtu $\gamma$ dla przyjętej w wyniku badań (lub założonej) wartości czasu (przebiegu) do uszkodzenia $\Theta_{b}$, minimalizując odchylenie średniokwadratowe rozkładu Frecheta od krzywej symptomowej. Jeśli przyjąć hipotezę, że wraz ze wzrostem $\Theta$ wielkość $\gamma$ będzie asymptotycznie dażyć do pewnej wartości (lub minimum) $\gamma_{u}$, to po przyjęciu miary kryterium zbieżności można określić wartość $\Theta$, która określa pierwszą fazę symptomowej krzywej życia. Z przebiegu zależności $\gamma(\Theta)$ można wnioskować o przydatności informacji uzyskanej $\mathrm{z}$ określonego punktu pomiarowego dla wybranego symptomu wibroakustycznego. 


\section{Przykładowe wyniki badań wybranych silników spa- linowych}

Do badań wybrano dwa silniki spalinowe typu 2112 SSF o numerach 28 i 128, dla których "czas" życia wyrażony przebiegiem do poważnego uszkodzenia układu korbowego był znany i wynosił odpowiednio 268,22 i 276,13 tys. km. Przeanalizowano rozwój trzech symptomów wibroakustycznych, a mianowicie: skutecznej wartości przyspieszeń drgań $\mathrm{A}_{\mathrm{sk}}$, skutecznej wartości prędkości drgań $\mathrm{V}_{\mathrm{sk}}$ oraz szczytowej wartości prędkości drgań $\mathrm{V}_{\mathrm{sz}}$, uzyskanych z różnych punktów pomiarowych, położonych na wysokości osi wału korbowego i zwrotu zewnętrznego tłoka (GMP). Na rysunku 1 przedstawiono schemat rozmieszczenia punktów pomiarowych sygnału drgań na badanych silnikach [3].

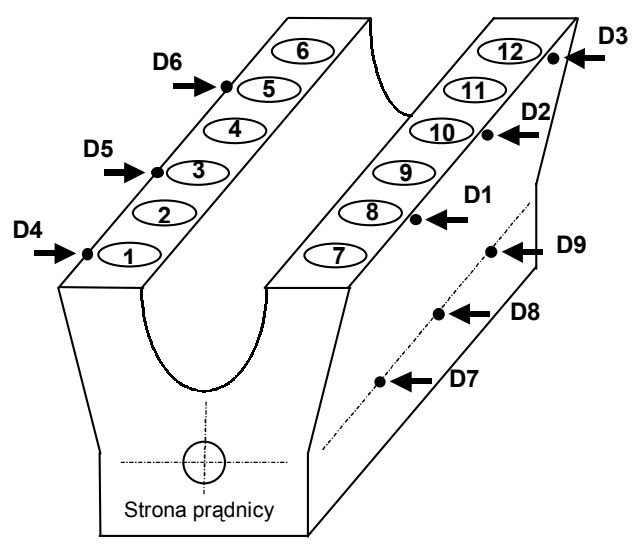

Rys. 1. Schemat rozmieszczenia punktów pomiarowych na silniku $2112 \mathrm{SSF}$

Na rysunku 2 i 3 przedstawiono przykładowe zmiany skutecznej wartości przyspieszeń drgań zmierzone w punkcie pomiarowym D2 silnika nr 28 oraz szczytowej wartości prędkości drgań w punkcie D8 silnika nr $128 \mathrm{w}$ funkcji przebiegu lokomotywy [3].

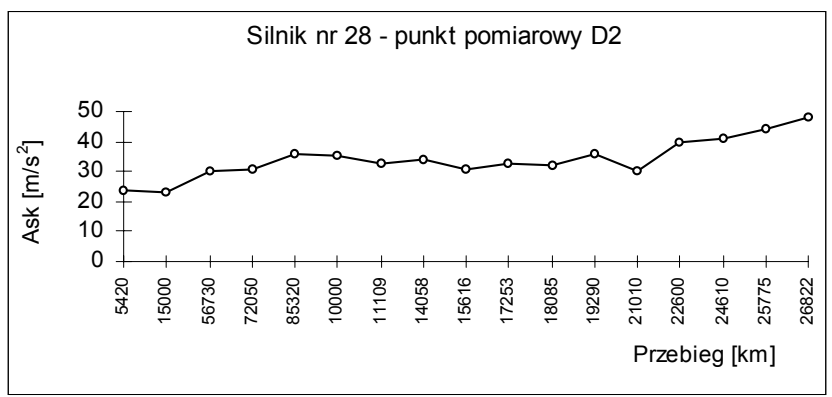

Rys. 2. Zmiany skutecznej wartości przyspieszeń drgań w punkcie D2 silnika nr 28

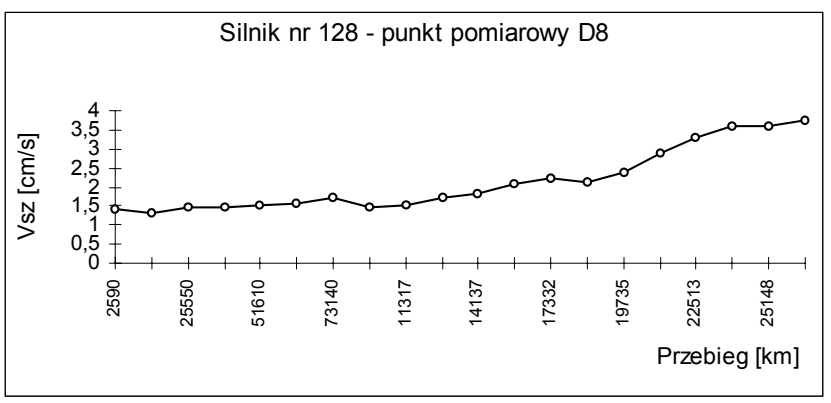

Rys. 3. Zmiany szczytowej wartości prędkości drgań w punkcie D8 silnika nr 128
Wybrane wyniki przeprowadzonych obliczeń szacowania zmian współczynnika kształtu $\gamma$ przedstawiono na rysunkach 4 do 7 . Do analizy współczynnika $\gamma$ przyjęto $\Theta_{\mathrm{b}}=300$ tys. $\mathrm{km}$, co jest przebiegiem do naprawy silnika oraz $\Theta_{\mathrm{b}}=500$ tys. $\mathrm{km}$, co jest przebiegiem teoretycznym możliwym do uzyskania przez badane silniki.

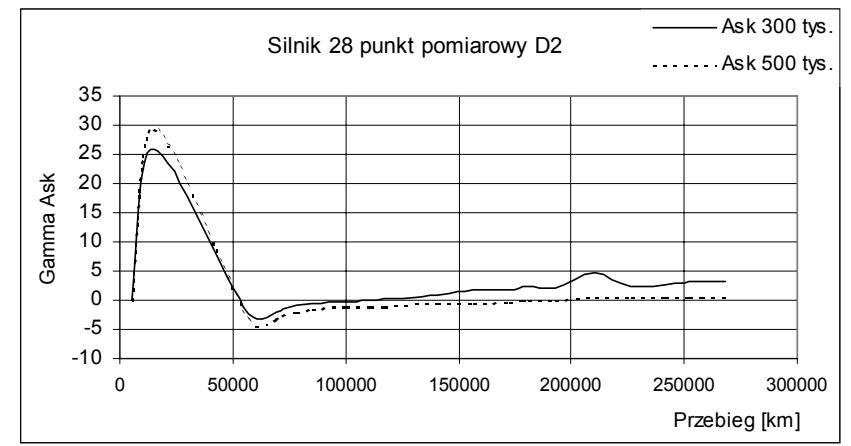

Rys. 4. Zmiana współczynnika kształtu $\gamma \mathrm{w}$ funkcji wartości skutecznej przyspieszenia drgań dla różnych oczekiwanych wartości przebiegu silnika do uszkodzenia (punkt pomiarowy D2)

Wartość współczynnika $\gamma$ po przebiegu około 60 tys. km (rys. 4) nie ulega już istotnym wahaniom, ale trudno mówić o stabilizacji. Ponadto wartości $\gamma$ zależą od przyjętej wstępnie wartości przebiegu do uszkodzenia. Oznacza to, że punkt D2 mógłby być dobrym punktem odbioru sygnału wibroakustycznego, ale skuteczna wartość przyspieszenia drgań nie jest dobrym symptomem wibroakustycznym.

$\mathrm{Na}$ rys. 5 przedstawiono przebieg zmienności współczynnika $\gamma$ dla tego samego punktu pomiarowego i skutecznej wartości prędkości drgań. Wartości oczekiwane przebiegu do uszkodzenia przyjęto - tak jak poprzednio na poziomie 300 tys. i 500 tys. $\mathrm{km}$.

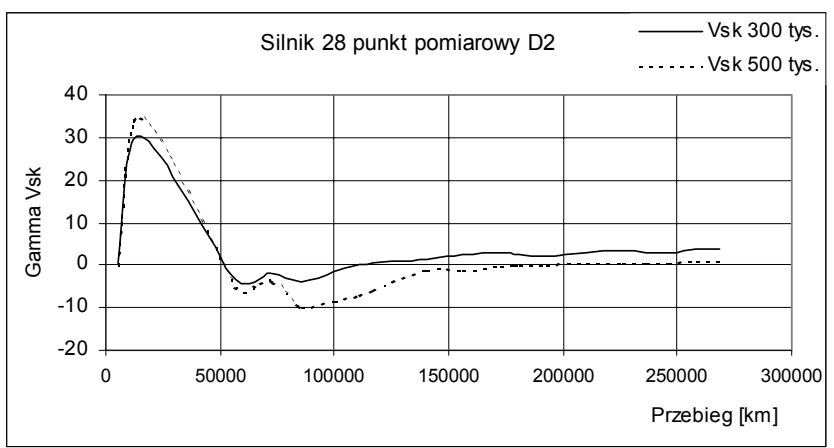

Rys. 5. Zmiana współczynnika kształtu $\gamma$ w funkcji wartości skutecznej prędkości drgań dla różnych oczekiwanych wartości przebiegu silnika do uszkodzenia (punkt pomiarowy D2)

Z rysunku 5 wynika, że skuteczna wartość prędkości drgań nie jest właściwym symptomem, a ponadto „stabilizacja” wartości współczynnika $\gamma$ następuje po dłuższym przebiegu niż w przypadku skutecznej wartości przyspieszeń drgań.

Przebieg współczynnika $\gamma$ dla szczytowej wartości prędkości drgań i punktu pomiarowego D2 przedstawiono na rysunku 6. 


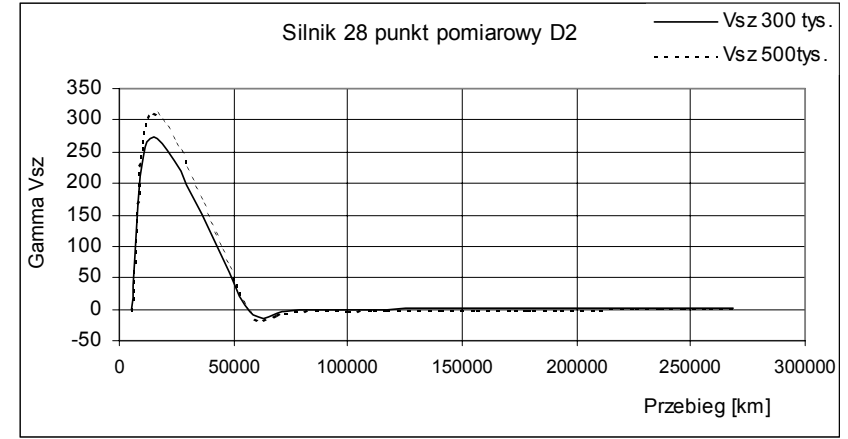

Rys. 6. Zmiana współczynnika kształtu $\gamma$ w funkcji wartości szczytowej prędkości drgań dla różnych oczekiwanych wartości przebiegu silnika do uszkodzenia (punkt pomiarowy D2)

Z przedstawionych rysunków wynika, że z rozpatrywanych symptomów wibroakustycznych najlepiej wybrać szczytową prędkość drgań. Spostrzeżenie to dotyczy jedynie wybranego punktu pomiarowego drgań D2, leżącego na wysokości zwrotu zewnętrznego tłoka (GMP) 10 cylindra (rys. 1) silnika nr 28.

Badania przebiegu współczynnika $\gamma \mathrm{w}$ funkcji przebiegu wykonano dla ośmiu punktów pomiarowych, trzech symptomów diagnostycznych i dwóch silników. Potwierdziły one wyżej przedstawione spostrzeżenie. Dowodem przyjęcia symptomu szczytowej wartości prędkości drgań jako najlepszego symptomu oraz punktu pomiarowego D8 jest przebieg współczynnika $\gamma$ dla symptomu szczytowej wartości prędkości drgań silnika nr 128. przedstawionego na rysunku 7.

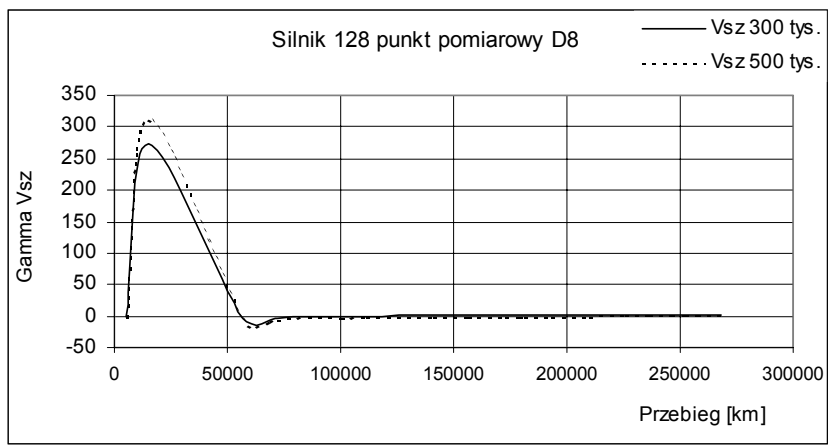

Rys. 7. Zmiana współczynnika kształtu $\gamma$ w funkcji wartości szczytowej prędkości drgań dla różnych oczekiwanych wartości przebiegu silnika do uszkodzenia (punkt pomiarowy D8)
Przebieg zmian współczynnika $\gamma$ dla różnych punktów pomiarowych potwierdził, że wybór punktu pomiarowego jest istotny i powinien być poprzedzony staranną analizą. Dla obu badanych silników najlepszymi punktami odbioru sygnału diagnostycznego okazały się: punkt D2 leżący na wysokości zwrotu zewnętrznego tłoka (GMP) 10 cylindra i punkt D8 znajdujący się na wysokości osi wału korbowego 8 cylindra (rys. 1).

\section{Podsumowanie}

Przedstawione rozważania wykazały, że zastosowanie modelu tribowibroakustycznego do wyboru symptomu diagnostycznego i punktu odbioru tego symptomu jest możliwe. Z przebiegu współczynnika kształtu $\gamma$ krzywej symptomowej w pierwszej fazie jej rozwoju można wysnuć wnioski o trafności wyboru zarówno punktu pomiarowego jak i symptomu. Im ta krzywa jest bardziej stroma, tym lepiej odzwierciedla ona rozwój procesu destrukcyjnego silnika w krzywej symptomowej. O trafności doboru symptomu i punktu pomiarowego można również wnioskować na podstawie wartości miary pracy silnika do "ustabilizowania" się wartości współczynnika kształtu $\gamma$ krzywej symptomowej oraz na podstawie wrażliwości tej krzywej na założony przebieg silnika do uszkodzenia.

Przedstawione wyniki i analizy dotyczące wyboru punktów pomiarowych oraz symptomów sygnału drganiowego znalazły praktyczne zastosowanie przy opracowaniu metody diagnozowania silników spalinowych 2112 SSF lokomotyw SP45. Metoda ta została zastosowana w Zakładzie Taboru w Poznaniu.

\section{Literatura}

[1] Cempel C., Diagnostyka wibroakustyczna maszyn, WPP Poznań, 1985.

[2] Kasprzak B., Zastosowanie modelu tribowibroakustycznego do oceny zasobu pracy silnika. Zeszyty Naukowe Politechniki Poznańskiej, WPP Poznań, 1994.

[3] Tomaszewski F., Zagadnienia wyznaczania stanu technicznego złożonego obiektu mechanicznego za pomoca sygnatu wibroakustycznego. Politechnika Poznańska 1998 - Seria Rozprawy nr 337. 